\begin{tabular}{|c|c|c|c|c|c|c|c|c|c|c|c|c|}
\hline \multirow{3}{*}{$\begin{array}{c}\mathrm{AFB}_{1} \\
\text { (ng/day) }\end{array}$} & \multirow{3}{*}{$\begin{array}{l}\text { Rat } \\
\text { ID\# }\end{array}$} & \multicolumn{9}{|c|}{ Day } & \multirow{3}{*}{$\begin{array}{c}\text { Group Average } \\
\text { Day } 9 \\
\text { (g) } \\
\end{array}$} & \multirow{3}{*}{$\begin{array}{l}\sigma_{\mathrm{n}-1} \\
(\mathbf{g})\end{array}$} \\
\hline & & 1 & 2 & 3 & 4 & 5 & 6 & 7 & 8 & 9 & & \\
\hline & & \multicolumn{9}{|c|}{ Body Weight (g) } & & \\
\hline \multirow{4}{*}{0} & 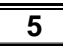 & 173 & 177 & 178 & 180 & 180 & 180 & 178 & 182 & 183 & \multirow{4}{*}{189} & \multirow{4}{*}{9} \\
\hline & 6 & 175 & 180 & 181 & 183 & 184 & 187 & 189 & 193 & 197 & & \\
\hline & 7 & 165 & 167 & 168 & 169 & 171 & 170 & 173 & 175 & 179 & & \\
\hline & 8 & 180 & 184 & 187 & 188 & 190 & 190 & 190 & 194 & 196 & & \\
\hline \multirow{4}{*}{0.01} & 9 & 165 & 165 & 167 & 171 & 172 & 172 & 175 & 177 & 180 & \multirow{4}{*}{189} & \multirow{4}{*}{7} \\
\hline & 10 & 170 & 171 & 171 & 174 & 177 & 180 & 180 & 185 & 188 & & \\
\hline & 11 & 171 & 174 & 177 & 179 & 181 & 182 & 185 & 188 & 190 & & \\
\hline & 12 & 178 & 179 & 181 & 184 & 187 & 189 & 191 & 195 & 198 & & \\
\hline \multirow{4}{*}{0.1} & 13 & 174 & 169 & 169 & 171 & 172 & 177 & 177 & 181 & 184 & \multirow{4}{*}{184} & \multirow{4}{*}{12} \\
\hline & 14 & 170 & 169 & 168 & 170 & 172 & 170 & 173 & 175 & 179 & & \\
\hline & 15 & 160 & 158 & 159 & 163 & 164 & 164 & 167 & 168 & 172 & & \\
\hline & 16 & 179 & 181 & 183 & 186 & 187 & 191 & 193 & 196 & 200 & & \\
\hline \multirow{4}{*}{1} & 17 & 175 & 178 & 179 & 180 & 181 & 181 & 182 & 183 & 187 & \multirow{4}{*}{189} & \multirow{4}{*}{6} \\
\hline & 18 & 169 & 172 & 174 & 176 & 180 & 181 & 184 & 185 & 188 & & \\
\hline & 19 & 179 & 183 & 183 & 186 & 186 & 187 & 191 & 193 & 197 & & \\
\hline & 20 & 166 & 168 & 167 & 171 & 173 & 172 & 176 & 178 & 182 & & \\
\hline \multirow{4}{*}{10} & 21 & 185 & 187 & 190 & 189 & 189 & 191 & 194 & 194 & 198 & \multirow{4}{*}{192} & \multirow{4}{*}{11} \\
\hline & 22 & 182 & 185 & 186 & 189 & 189 & 192 & 195 & 199 & 202 & & \\
\hline & 23 & 181 & 183 & 184 & 184 & 186 & 188 & 189 & 192 & 192 & & \\
\hline & 24 & 166 & 167 & 167 & 169 & 167 & 170 & 172 & 172 & 176 & & \\
\hline \multirow{4}{*}{100} & 25 & 182 & 182 & 184 & 184 & 185 & 188 & 190 & 195 & 196 & \multirow{4}{*}{195} & \multirow{4}{*}{4} \\
\hline & 26 & 184 & 186 & 189 & 190 & 188 & 191 & 192 & 197 & 200 & & \\
\hline & 27 & 179 & 180 & 182 & 180 & 183 & 185 & 185 & 190 & 193 & & \\
\hline & 28 & 184 & 185 & 188 & 187 & 187 & 187 & 187 & 187 & 190 & & \\
\hline \multirow{4}{*}{1000} & 29 & 191 & 196 & 200 & 201 & 203 & 205 & 208 & 203 & 207 & & \\
\hline & 30 & 165 & 167 & 168 & 170 & 169 & 172 & 174 & 173 & 176 & 191 & 13 \\
\hline & 31 & 175 & 177 & 181 & 183 & 185 & 187 & 189 & 188 & 192 & 191 & 13 \\
\hline & 32 & 177 & 182 & 185 & 186 & 183 & 185 & 188 & 188 & 190 & & \\
\hline & 33 & 190 & 191 & 190 & 190 & 189 & 187 & 188 & 191 & 196 & & \\
\hline $100 \cap 0$ & 34 & 175 & 176 & 174 & 174 & 173 & 171 & 173 & 175 & 176 & 170 & 12 \\
\hline 10000 & 35 & 169 & 168 & 168 & 169 & 166 & 166 & 164 & 169 & 171 & $1 / 9$ & 12 \\
\hline & 36 & 170 & 169 & 169 & 171 & 169 & 167 & 167 & 170 & 173 & & \\
\hline
\end{tabular}

\title{
Supplemental Table 1
}




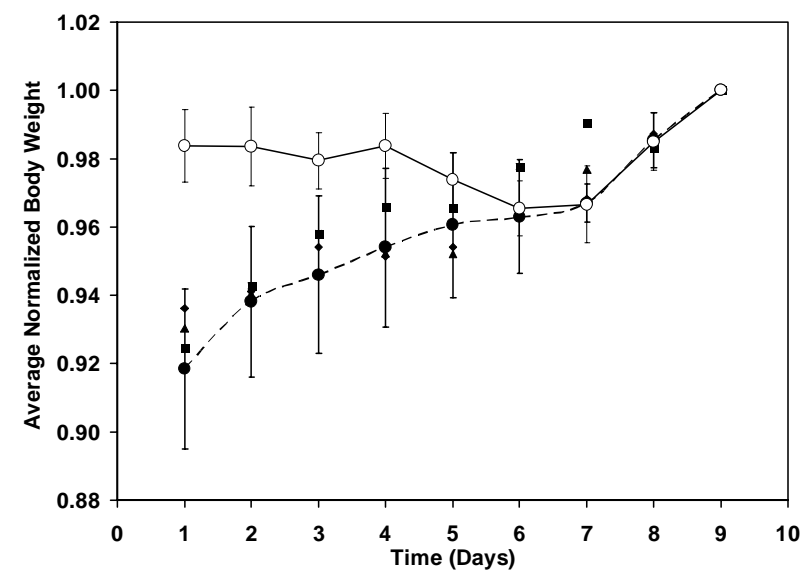

Supplemental Figure 1 